\title{
Interferência do arranjo de plantas daninhas no crescimento do feijoeiro
}

\section{Patrícia Lage $^{1}$, Marcos Antônio da Silveira Júnior ${ }^{1}$, Evander Alves Ferreira ${ }^{1}$, Gustavo Antônio Mendes Pereira², Enilson de Barros Silva ${ }^{1}$}

\author{
${ }^{1}$ Universidade Federal dos Vales do Jequitinhonha e Mucuri, Campus JK, Diamantina, Minas Gerais, Brasil. E-mail: \\ patricialage.biologa@gmail.com, silveirajr@hotmail.com, evanderalves@gmail.com, enilson.barros.silva@gmail.com \\ ${ }^{2}$ Universidade Federal de Viçosa, Viçosa-MG, Brasil. E-mail: gustavogamp@ hotmail.com
}

Recebido: 21/03/2017; Aceito: 03/08/2017.

\section{RESUMO}

A competição com plantas daninhas afeta diretamente a produtividade do feijoeiro. Objetivou-se com este trabalho investigar a interferência de duas principais plantas daninhas que ocorrem na cultura do feijoeiro e o efeito da associação (comunidades) dessas plantas no desenvolvimento da cultura. Foram estudados dois fatores constituídos pela combinação de cinco densidades de infestação de plantas daninhas (fator A) e duas espécies de plantas daninhas, Urochloa plantaginea (capim-marmelada) e Bidens pilosa (picão-preto) e a associação das duas (capim-marmelada + picão-preto) (fator B). Foram avaliadas a massa da matéria seca foliar, do caule, da raiz, da parte reprodutiva, total e da parte aérea e a taxa de crescimento da cultura. Verificou-se que o picão-preto exerceu maior competição sobre o feijoeiro do que o capim-marmelada. Houve menor redução da MST e TCC em competição com capim-marmelada. Destacando-se que MST e TCC foram mais afetadas negativamente quando cultivado na presença de capim-marmelada e picão-preto simultaneamente (arranjo feijoeiro + picão-preto + capim-marmelada). Conclui-se que as plantas de picão-preto e capim-marmelada em convivência de plantas de feijão afetam o desenvolvimento da cultura. O picão-preto exerce maior competição sofre o feijoeiro do que o capim-marmelada. A associação das plantas daninhas é mais prejudicial à cultura do que isoladas.

Palavras-chave: Urochloa plantaginea, Bidens pilosa, Phaseolus vulgaris.

\section{Interference of weed arrangement in bean growth}

\begin{abstract}
Weed competition directly affects bean productivity. The objective of this work was to investigate the interference of two major plants that occur in the bean crop and the effect of the association (communities) on the nondevelopment of the crop. Two factors consisting of the combination of five weed infestation densities (factor A) and two weed species, Urochloa plantaginea and Bidens pilosa (factor B), were studied. The mass of the secular leaf material, the stem, the root, the reproductive, total and aerial parts and a growth rate of the culture were evaluated. It was found that Bidens pilosa exercised greater competition with the common bean that makes Urochloa plantaginea. There was a smaller reduction of MST and CBT in competition with Urochloa plantaginea. It was observed that MST and CBT were negatively affected when cultivated in the presence of Urochloa plantaginea and Bidens pilosa simultaneously (bean + Bidens pilosa + Urochloa plantaginea arrangement). It is concluded as plants of Bidens pilosa and Urochloa plantaginea in coexistence of bean plants, affect the development of the crop. Bidens pilosa exerts greater competition with common bean than Urochloa plantaginea. The association of weeds is more harmful to the crop than isolated
\end{abstract}

Key words: Urochloa plantaginea, Bidens pilosa, Phaseolus vulgaris. 


\section{Introdução}

O feijoeiro comum (Phaseolus vulgaris L.) é uma importante fonte de alimento, sendo fonte de proteína na dieta alimentar do povo brasileiro. Para a safra 2015/2016, a área cultivada no Brasil foi de 3,13 milhões de hectares, gerando uma produção de 3,38 milhões de toneladas com produtividade média de 1082 $\mathrm{kg} \mathrm{ha}^{-1}$ (CONAB, 2016).

Em regiões de cerrado, onde as condições climáticas são bem definidas, o feijoeiro é cultivado em três épocas: "águas", "seca" e "outono-inverno", contudo, a primeira safra (águas) tem apresentado os maiores problemas no controle de plantas daninhas devido, sobretudo, à boa disponibilidade hídrica associada à intensa radiação solar, favorecendo, consequentemente, a infestação de plantas daninhas com metabolismo $\mathrm{C}_{4}$, como por exemplo, capim-marmeladas (Brachiaria spp.), capim carrapicho (Cenchrus echinatus), gramaseda (Cynodon dactylon), capim-colonião (Panicum maximum), capim-pé-de-galinha (Eleusine indica), capim-favorito (Digitaria horizontalis) e tiririca (Cyperus rotundus) (COBUCCI, 2008). Na safra da "seca" e de "outono-inverno", apesar da menor influência dos fatores do meio (disponibilidade hídrica e radiação solar) sobre a comunidade infestante, o que acaba por favorecer o desenvolvimento das plantas do feijão e aumentar seu potencial competitivo, a interferência das plantas daninhas ainda é relevante e bem menos abordada em estudos sobre o assunto.

A interferência das plantas daninhas é considerada um dos fatores que contribuem para a baixa produtividade do feijoeiro. A cultura normalmente é bastante sensível a mato-interferência, que pode reduzir em até 50-70\% na produtividade dos grãos (MANABE et al., 2015). Dos trabalhos feitos no Brasil relacionados ao controle de plantas daninhas na cultura do feijoeiro, a maioria se refere ao controle com herbicidas. São raros os trabalhos que visam levantar subsídios para o estabelecimento de programa de manejo integrado de plantas daninhas nessa cultura. Devido à escassez de informações devem ser considerados prioritários trabalhos que objetivam estudar os efeitos de períodos de convivência e de controle das plantas daninhas sobre a produtividade da cultura do feijoeiro (SALGADO et. al., 2007).

O feijoeiro, por ser de baixa capacidade competitiva, é enquadrado no grupo de culturas que menos sombreiam o solo, logo, sofre intensa interferência das plantas daninhas, resultando, por conseguinte, em sérios prejuízos no crescimento, produtividade e na operacionalização de colheita. Essa redução é ocasionada principalmente pela competição por água, luz e nutrientes (COBUCCI, 2008). Certas espécies de plantas daninhas como a Ipomea spp. afetam também a colheita manual ou mecânica do feijão, particularmente quando a maturação das espécies é diferenciada.
De acordo com Silva \& Silva, (2013) o período entre o vigésimo e o quinquagésimo dia após a emergência das culturas é onde a competição ocorre de forma mais intensa entre plantas daninhas e culturas anuais como o feijoeiro, soja e milho. Além disso, esses autores ponderam ainda que tal competição depende de uma série de fatores relacionados à cultura ou à própria planta daninha como variedade, espaçamento, densidade e adubação do feijoeiro, tipo de planta infestante, densidade de ocorrência e período de interferência das plantas daninhas. Dentre estes fatores destacam-se a densidade e tipo de plantas daninhas e a época em que a competição ocorre (JAKELAITIS et al., 2006).

O manejo de plantas daninhas envolve atividades dirigidas para as plantas daninhas (manejo direto) e/ou para o sistema formado pelo solo e pela cultura (manejo indireto). $\mathrm{O}$ manejo direto refere-se à eliminação direta das plantas daninhas com uso de herbicidas, ação mecânica ou manual e ação biológica. No manejo do solo (manejo indireto) se trabalha com a relação sementes ativas e inativas. Neste caso, aumenta-se a germinação das plantas daninhas e posteriormente realiza-se o controle com o uso de técnicas como, por exemplo, a aplicação sequencial de dessecantes. O manejo cultural se baseia na construção de plantas de feijoeiro com capacidade de manifestar seu máximo potencial produtivo e competir com as plantas daninhas, pela utilização de práticas como o equilíbrio na fertilidade do solo, velocidade correta de semeadura, manejo de adubação, arranjo espacial das plantas, época adequada de plantio, dentre outros.

A terminologia 'controle integrado' significa a utilização de dois ou mais métodos de controle de plantas daninhas objetivando manter as populações abaixo do nível de dano econômico e com o mínimo de impacto ambiental, englobando os métodos preventivos, cultural, mecânicos, físicos, biológicos e químicos. De acordo com a condição edafoclimática como a topografia do terreno, o tipo de solo ou a precipitação pluvial e em função das espécies de plantas daninhas presentes e dos tipos de equipamentos disponíveis define-se o método ou a associação de métodos de controle de plantas daninhas que permitam ao produtor maior eficiência, economia e preservação do meio ambiente. A utilização de um único método de controle por anos consecutivos pode acarretar sérios problemas na área, tais como: adensamento do solo; acúmulo de resíduos de herbicidas; e seleção de plantas daninhas resistentes (COBUCCI, 2008).

Objetivou-se com esse estudo verificar a interferência de duas principais plantas daninhas altamente competitivas com a cultura (capimmarmelada e picão-preto) e a associação dessas duas espécies no crescimento de plantas de feijoeiro no período de outono-inverno. 


\section{Material e Métodos}

$\mathrm{O}$ experimento foi conduzido entre os meses de maio a agosto de 2013 sendo instalado nas dependências da Universidade Federal dos Vales do Jequitinhonha e Mucuri - Diamantina/MG, em ambiente protegido, mantido sob iluminação natural. No período de invernoprimavera, a temperatura média em Diamantina foi de $20{ }^{\circ} \mathrm{C}$; dentro da casa de vegetação a temperatura se manteve em $25^{\circ} \mathrm{C}$ (Figura 1).

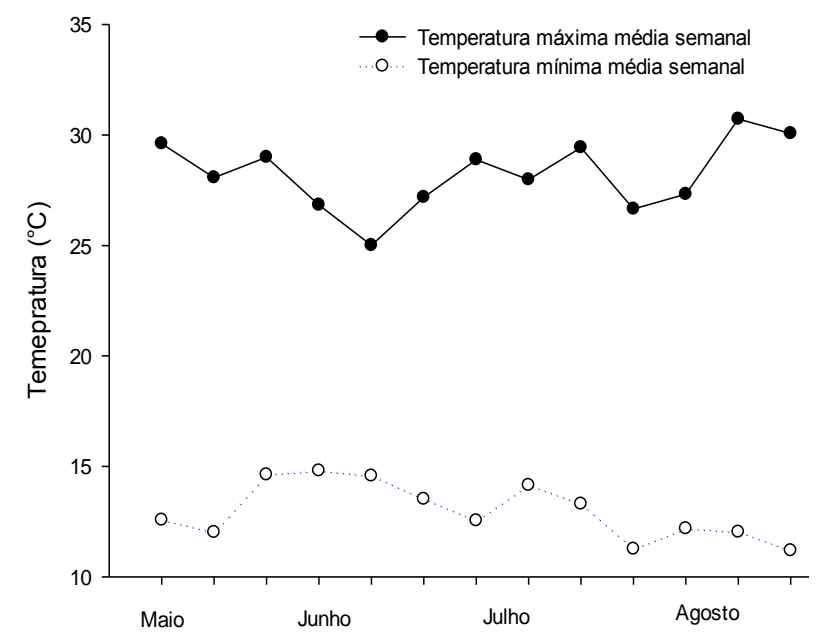

Figura 1. Média das temperaturas máximas e mínimas em Diamantina-MG no período de condução do experimento (maio-agosto/2013).

As unidades experimentais constaram de vasos plásticos com volume de 10 litros, perfurados no fundo, contendo Latossolo Vermelho, corrigido e adubado, com incorporação do calcário e adubação feitas um mês antes da implantação do experimento.

$\mathrm{O}$ solo de textura média apresentou os seguintes resultados na análise química: $\mathrm{pH}$ (água) de 5,0; teor de matéria orgânica de $4,7{\text { daq } \mathrm{kg}^{-1}}^{-} \mathrm{P}, \mathrm{K}$ e Ca de 1,3; $47 \mathrm{e}$ 2,4 $\mathrm{mg} \mathrm{dm}^{-3}$, respectivamente; $\mathrm{Mg}, \mathrm{Al}, \mathrm{H}+\mathrm{Al} \mathrm{e}$ $\mathrm{CTC}_{\text {efetiva }}$ de 1,$2 ; 0,1 ; 7,1$ e 3,8 cmolc $\mathrm{dm}^{-3}$, respectivamente. Para adequação do substrato quanto à nutrição, foram aplicados $3,0 \mathrm{~g} \mathrm{dm}^{-3}$ de calcário dolomítico e 3,0 $\mathrm{g} \mathrm{dm}^{-3}$ da formulação 4-14-8 $\left(\mathrm{N}_{-} \mathrm{P}_{2} \mathrm{O}_{5^{-}}\right.$ $\mathrm{K}_{2} \mathrm{O}$ ). As irrigações foram realizadas diariamente de forma a manter os vasos próximos à capacidade de campo.

Utilizou-se a cultivar do grupo carioca (IPR Eldorado), de ciclo curto e pertencente ao tipo II, delineamento experimental inteiramente casualizado com quatro repetições. $\mathrm{O}$ arranjo utilizado foi o fatorial $5 \times 3$ constituído pela combinação de cinco densidades de infestação de plantas daninhas, sendo elas: 0, 74, 147, 221 e 295 plantas $\mathrm{m}^{-2}$ e duas espécies de plantas daninhas, Urochloa plantaginea (capim-marmelada), Bidens pilosa (picão-preto) e a associação das duas espécies. Em cada unidade experimental foi semeada uma planta de feijão (Phaseolus vulgaris L.) e 10 sementes das respectivas espécies de plantas daninhas, sendo, posteriormente, realizado o desbaste de acordo com as densidade e comunidades propostas:

\section{Comunidade 1:}

Densidade 1 - uma planta de feijoeiro por vaso + 0,00 plantas capim-marmelada $\mathrm{m}^{-2}$;

Densidade 2 - uma planta de feijoeiro +74 plantas de capim-marmelada $\mathrm{m}^{-2}$;

Densidade 3 - uma planta de feijoeiro +147 plantas de capim-marmelada $\mathrm{m}^{-2}$;

Densidade 4 - uma planta de feijoeiro +221 plantas de capim-marmelada $\mathrm{m}^{-2}$;

Densidade 5 - uma planta de feijoeiro +295 plantas de capim-marmelada $\mathrm{m}^{-2}$.

\section{Comunidade 2:}

Densidade 1 - uma planta de feijoeiro por vaso + 0,00 plantas picão-preto $\mathrm{m}^{-2}$;

Densidade 2 - uma planta de feijoeiro +74 plantas de picão-preto $\mathrm{m}^{-2}$;

Densidade 3 - uma planta de feijoeiro +147 plantas de picão-preto $\mathrm{m}^{-2}$;

Densidade 4 - uma planta de feijoeiro +221 plantas de picão-preto $\mathrm{m}^{-2}$;

Densidade 5 - uma planta de feijoeiro +295 plantas de picão-preto $\mathrm{m}^{-2}$.

\section{Comunidade 3:}

Densidade 1 - uma planta de feijoeiro por vaso + 0,00 plantas daninhas $\mathrm{m}^{-2}$;

Densidade 2 - uma planta de feijoeiro +37 plantas de picão-preto $m^{-2}+37$ plantas de picão-preto $m^{-2}$;

Densidade 3 - uma planta de feijoeiro $+73,5$ plantas de picão-preto $\mathrm{m}^{-2}+73,5$ plantas de picão-preto $\mathrm{m}^{-2}$;

Densidade 4 - uma planta de feijoeiro $+110,5$ plantas de picão-preto $\mathrm{m}^{-2}+110,5$ plantas de picãopreto $\mathrm{m}^{-2}$;

Densidade 5 - uma planta de feijoeiro $+147,5$ plantas de picão-preto $\mathrm{m}^{-2}+147,5$ plantas de picãopreto $\mathrm{m}^{-2}$.

Aos 50 dias após a emergência e convivência da cultura com as espécies infestantes, determinou-se massa da matéria seca foliar (MSF (g)), massa da matéria seca do caule (MSC (g)), massa da matéria seca da raiz (MSR (g)), massa da matéria seca da parte reprodutiva (MSPR $(\mathrm{g})$ ), massa da matéria seca total (MST (g)=MSF+MSC+MSR+MSPR) e massa da matéria seca da parte aérea (MSPA (g)) através da retirada das plantas de feijoeiro na fase fenológica de formação das vargens separando-as em raízes, caules, folhas e parte reprodutiva para cada tratamento e as amostras foram secas em estufa com circulação de ar forçado a $65^{\circ} \mathrm{C}$, até massa constante e utilizou-se uma balança analítica para determinação da massa do material. 
Ressalta-se que esse intervalo de 50 dias foi estabelecido com o intuito de quantificar os prejuízos do feijoeiro durante o período de convivência com as espécies infestantes. Ademais, avaliou-se a taxa de crescimento da cultura (TCC $=$ massa da matéria seca total/número de dias até a colheita) e a relação entre parte aérea e radicular (MSPA/MSR).

Todos os dados referentes às três espécies avaliadas foram submetidos à análise de variância a $5 \%$ de significância e os modelos de regressão foram escolhidos com base na significância dos coeficientes de regressão, do coeficiente de determinação e do fenômeno biológico em estudo utilizando-se o software Sisvar $5.6^{\circledR}$ para as análises estatísticas e o Sigmaplot $12.5^{\circledR}$ para a confecção dos gráficos.

\section{Resultados e Discussão}

Quanto às variáveis avaliadas nas plantas de feijoeiro observou-se ajuste adequado ( $\mathrm{p}<0,001$ e $\mathrm{p}<$ $0,005)$ entre massa da matéria seca foliar (MSF), massa da matéria seca do caule (MSC), massa da matéria seca da raiz (MSR), massa da matéria seca da parte reprodutiva (MSPR), massa da matéria seca total (MST), taxa de crescimento da cultura (TCC), massa da matéria seca da parte aérea (MSPA) e relação entre parte aérea e radicular (MSPA/MSR) cultivado em competição com capim-marmelada e picão-preto em diferentes densidades e arranjos.

Ao avaliar a MSF das plantas de feijoeiro, verificouse que nas parcelas em que a cultura foi cultivada juntamente com plantas de picão-preto e nas parcelas em que cresceu com o capim-marmelada, bem como nos tratamentos em que competiu com picão-preto + capim-marmelada (comunidade envolvendo as três espécies), os valores médios dessa variável se reduziram de forma linear (Figura 2). No arranjo em que estavam presentes as três espécies, constatou-se maior inclinação da reta quando comparadas com as parcelas onde o feijoeiro cresceu em competição somente com o picãopreto e o capim-marmelada.

Conforme Santos et al. (2003), o feijoeiro apresenta menor proporção de folhas antes do florescimento em relação às plantas de picão-preto. Esse fato pode sugerir uma adaptação da espécie daninha na captação de luz nas fases iniciais do ciclo, ressalta-se, todavia, que o feijoeiro é uma espécie tolerante ao sombreamento, com capacidade de apresentar crescimento adequado em ambientes pouco iluminados. Tal adaptação não foi observada pelos mesmos autores em capim-marmelada.

Ronchi e Silva (2006) em estudo da interferência da densidade de plantas daninhas em mudas de cafeeiro, evidenciaram redução severa da altura, número de folhas e biomassa seca da parte aérea das mudas de café em coexistência com Commelina diffusa, principalmente nas maiores densidades.

Procópio et al. (2004) trabalhando com feijoeiro em competição com diferentes espécies de plantas daninhas constataram maior acúmulo de biomassa seca total do feijão frente a diversas espécies daninhas avaliadas devido a maior velocidade de emergência da cultura (até cinco dias antes das outras espécies). No presente trabalho destaca-se que o feijoeiro e o picão-preto emergiram simultaneamente, já o capim-marmelada emergiu dois dias depois (dados não mostrados), destacando que as três espécies foram semeadas simultaneamente.

Massa da matéria seca foliar

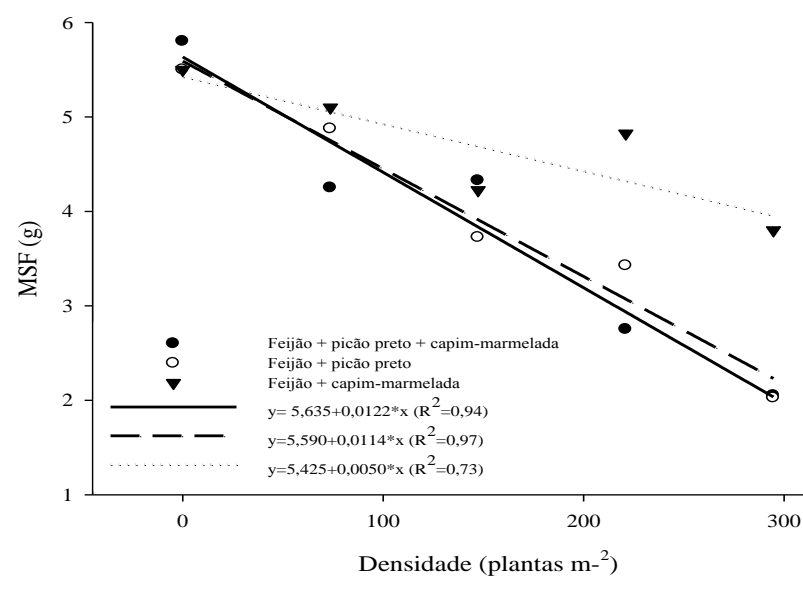

Figura 2. Matéria seca foliar (MSF), de feijoeiro cultivado em competição com capim-marmelada e picão-preto em diferentes densidades e arranjos

A MSC das plantas de feijoeiro foi afetada negativamente nas parcelas em que a cultura cresceu conjuntamente com picão-preto + capim-marmelada (comunidade envolvendo as três espécies), sendo que o gráfico apresentou decréscimo linear nos valores dessa variável com o incremento da densidade de plantas daninhas (Figura 3). Este comportamento pode estar relacionado à ocorrência de estiolamento das plantas de feijoeiro na medida em que o aumento da densidade tende a incrementar a estatura, reduzindo o diâmetro do caule, ocorrendo um decréscimo no número de folhas e ramificações como resposta à competição por luz na cultura.

Ao analisar a MSR nas plantas de feijoeiro competindo com capim-marmelada + picão-preto, verificou-se tendência acentuada de declínio nos valores dessa variável até aproximadamente na densidade de 221 plantas daninhas $\mathrm{m}^{-2}$, seguido de um pequeno acréscimo nos valores da MSR na maior densidade. Já para os arranjos feijoeiro + picão-preto e feijoeiro + capim-marmelada verificou-se incremento nos valores de MSR até aproximadamente a densidade de 147 
plantas infestantes $\mathrm{m}^{-2}$ seguida de decréscimo nas médias de MSR com o aumento da população de plantas (Figura 4).

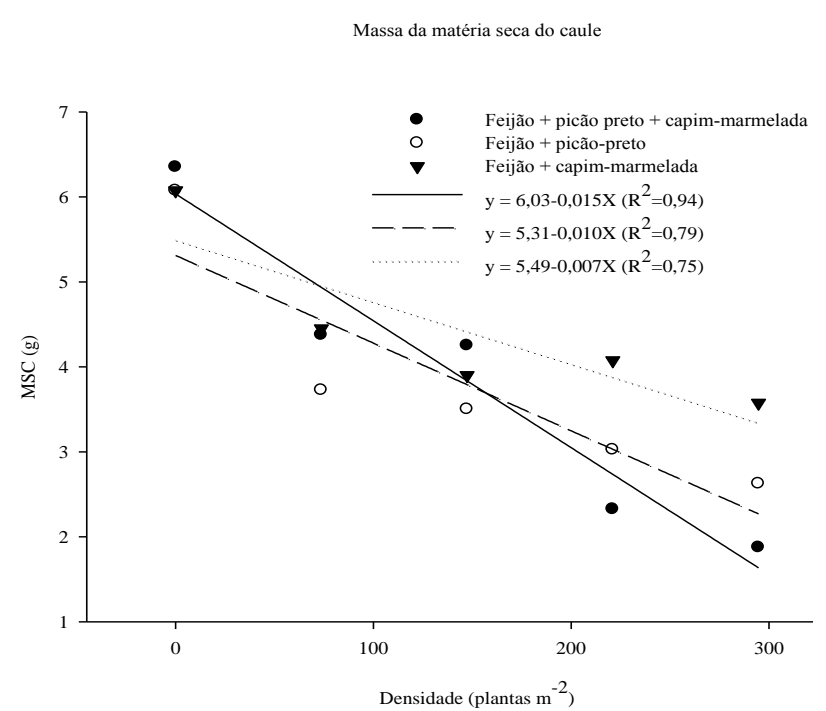

Figura 3. Matéria seca do caule (MSC) de feijoeiro cultivado em competição com capim-marmelada e picão-preto em diferentes densidades e arranjos.

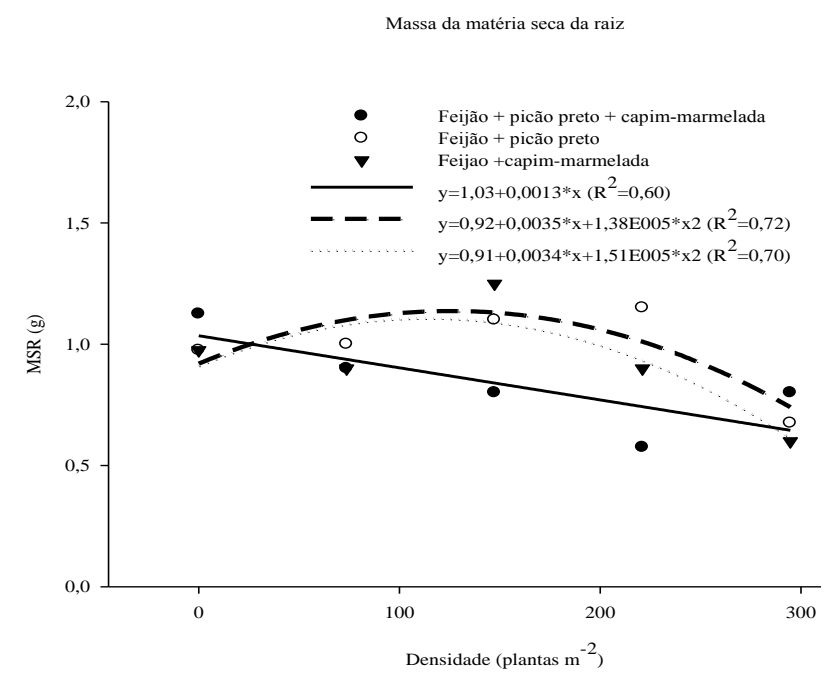

Figura 4. Matéria seca da raiz (MSR) de feijoeiro cultivado em competição com capim-marmelada e picão-preto em diferentes densidades e arranjos.

Nos arranjos feijoeiro + capim-marmelada e feijoeiro + picão-preto, verificou-se comportamento quadrático da curva com o aumento da densidade de plantas daninhas para a matéria seca da raiz. De fato, notou-se redução nos valores dessa variável até a densidade aproximada de 221 plantas daninhas $/ \mathrm{m}^{-2}$, seguida de incremento nesses valores nos dois arranjos, destacando-se que o arranjo feijão + picão-preto promoveu maior decréscimo nos valores da MSC quando comparado ao arranjo feijoeiro + capimmarmelada nas densidades intermediárias (Figura 4).

De maneira geral os números mostram que o nível de competição influenciou negativamente o acúmulo da
MSR com o aumento da densidade das plantas daninhas, isso se for considerada apenas a maior densidade de plantas. No entanto, ao avaliar o efeito dos arranjos feijoeiro + picão-preto e feijoeiro + capimmarmelada constatou-se incremento no crescimento do sistema radicular com o aumento da densidade de plantas; o crescimento do sistema radicular nas densidades mais baixas de competição pode ser visto como uma forma de defesa da planta de feijoeiro na disputa por recursos e espaço no solo (Figura 4). Em condições de estresse hídrico ou nutricional a planta tende a produzir maior proporção de sistema radicular em relação à parte aérea como forma de incrementar sua capacidade de absorção de água e nutrientes (TAIZ \& ZEIGER, 2014). Destacando-se também que em uma situação de competição onde as três espécies extraem água e nutrientes do meio, esses recursos podem ser reduzidos no ambiente edáfico.

Cury et al. (2011) concluíram que o potencial agressivo de $U$. plantaginea em nível radicular em densidades moderadas competindo com plantas de feijoeiro, cultivar Pérola, induz a maior alocação relativa de matéria seca para os órgãos superiores na tentativa de sobreviver à competição.

No presente estudo ao avaliar conjuntamente a MSR e MSC constatou-se que nos arranjos em que o feijoeiro cresce somente com plantas de capim-marmelada e no arranjo em que a cultura cresceu com o picão-preto, o comportamento da curva (quadrática) é inverso. Com a concavidade voltada para cima para a variável MSC e concavidade voltada para baixo quando da variável MSR, nas densidades moderadas de plantas infestantes (147 e 221 plantas daninhas $\mathrm{m}^{-2}$ ), a cultura do feijoeiro mostra tendência de produzir maior proporção de sistema radicular em relação a parte aérea em condição moderada de competição (Figura 4).

Com relação à MSPR de plantas de feijoeiro, constatou-se tendência de redução nos valores dessa variável com o incremento da densidade de plantas daninhas nas parcelas em que o feijoeiro foi cultivado isoladamente com capim-marmelada, plantas de picãopreto e em comunidade (presença das três espécies); ressaltando que a presença das três espécies afetou de forma mais acentuada a MSPR (Figura 5).

Plantas de feijoeiro mostraram menor redução da MST e TCC quando cultivadas em competição em densidades crescentes de plantas de capim-marmelada comparada às parcelas onde a cultura foi cultivada nos arranjos feijoeiro + picão-preto e feijoeiro + picão-preto + capim-marmelada, destacando-se que, o acúmulo de massa seca total e a taxa de crescimento do feijoeiro foram mais afetadas negativamente quando cultivado na presença de capim-marmelada e picão-preto simultaneamente (arranjo feijoeiro + picão-preto + capim-marmelada) (Figuras 6 e 7). 
Massa da materia seca da parte reprodutiva

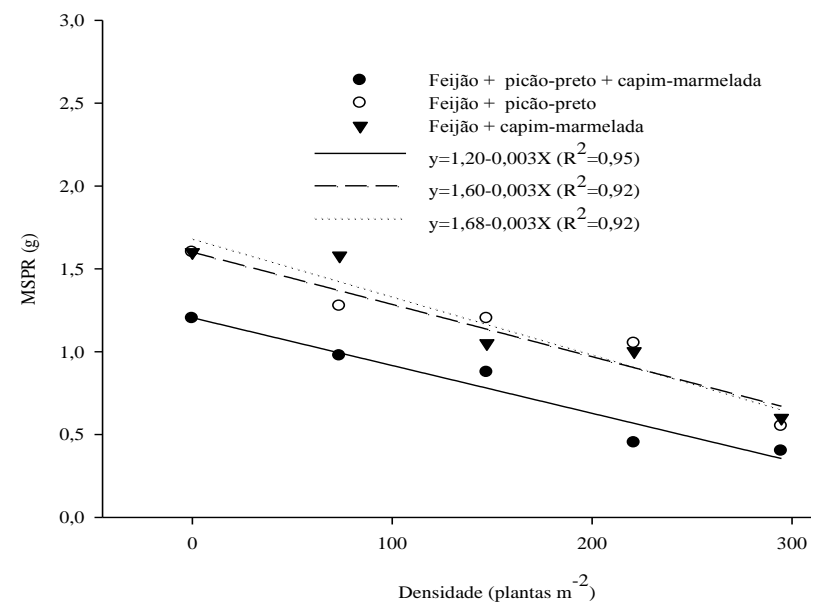

Figura 5. Matéria seca da parte reprodutiva (MSPR) de feijoeiro cultivado em competição com capim-marmelada e picão-preto em diferentes densidades e arranjos.

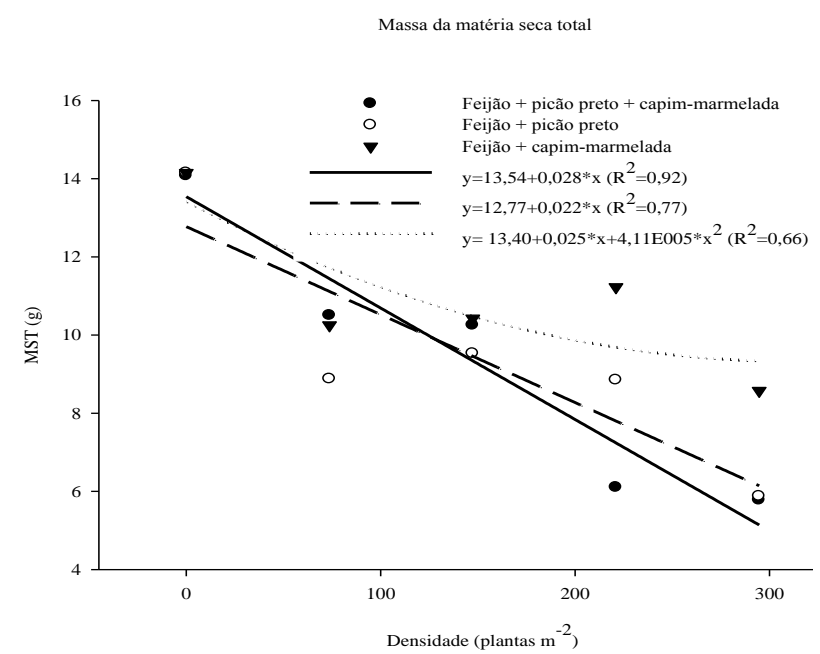

Figura 6. Matéria seca total (MST) de feijoeiro cultivado em competição com capim-marmelada e picão-preto em diferentes densidades e arranjos.

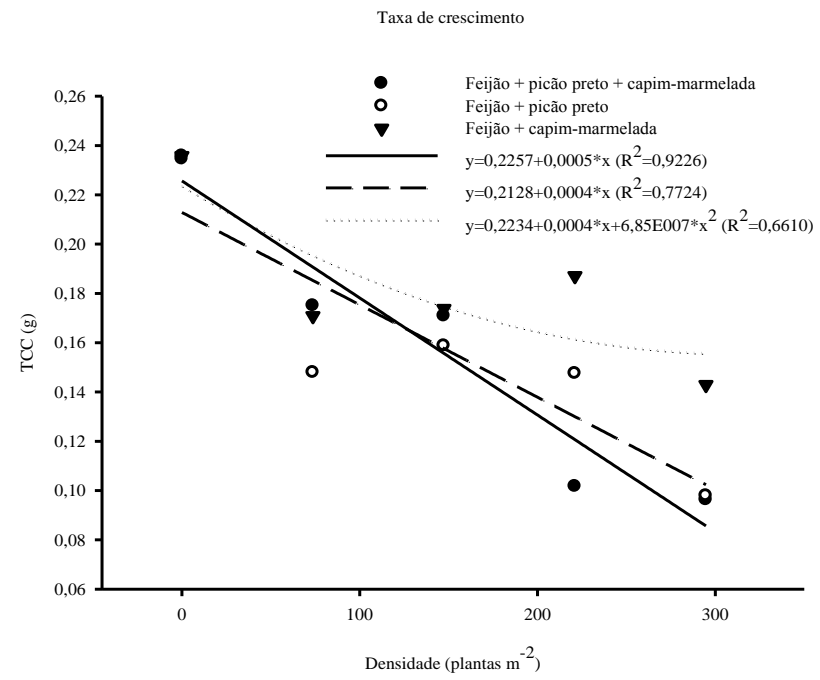

Figura 7. Taxa de crescimento da cultura (TCC) de feijoeiro cultivado em competição com capim-marmelada e picão-preto em diferentes densidades e arranjos.
Ambas as espécies daninhas se caracterizam por serem de ampla distribuição nacional e muito competitiva, principalmente com culturas anuais provocando prejuízos consideráveis ao rendimento e qualidade da produção (SANTOS; CURY, 2011). Manabe et al. (2015) concluíram que a baixa TCC em plantas de feijoeiro aos 60 dias após a emergência quando em convivência com as plantas daninhas demonstra que, geralmente, as plantas cultivadas têm menor capacidade competitiva em razão do processo de melhoramento pelo qual passaram do que espécies da comunidade infestante (plantas não cultivadas); como consequência, apresentam menor tolerância aos efeitos da competição (FONTES et al., 2003). Outro fator a se considerar é que as plantas daninhas geralmente ocorrem em altas densidades nos campos de produção o que aumenta muito sua capacidade competitiva por recursos no solo, luz e principalmente espaço (BARCELLOS Jr. et al., 2016).

Importante destacar que o cultivar de feijoeiro utilizado no presente trabalho é classificado como pertencente ao tipo II, ou seja, crescimento indeterminado e porte ereto, sendo indicado para produtores que utilizam elevado nível tecnológico e colheita mecanizada. Em relação à capacidade de competição da planta de feijão pode-se dizer que sua morfologia é fator preponderante na medida que genótipos de hábitos de crescimento dos tipos I e II, com porte ereto e poucos ramificados, são menos competitivos. Por outro lado, os genótipos tipo III, os mais cultivados, promovem maior cobertura do solo (SANTOS; GAVILANES, 2006).

Os tratamentos relacionados à variável MSPA mostraram comportamento linear decrescente com o incremento da densidade de plantas; salientando que as parcelas onde o feijoeiro esteve juntamente com plantas de capim-marmelada (arranjo feijoeiro + capimmarmelada) houve menor inclinação da reta com aumento da população dessa planta daninha (Figura 8).

Com relação às parcelas em que o feijoeiro foi cultivado na presença de densidades crescentes de plantas de picão-preto e no arranho feijoeiro + picãopreto + capim-marmelada as retas ajustadas para a variável (MSPA) referentes a esses dois arranjos apresentaram maior inclinação, indicando efeito mais severo desses arranjos no crescimento da parte aérea do feijoeiro (Figura 8).

Plantas de feijoeiro cultivadas em associação com picão-preto e capim-marmelada (feijoeiro + picão-preto + capim-marmelada) mostraram inicialmente elevação dos valores médios da relação MSPA/MSR até aproximadamente 74 plantas daninhas $\mathrm{m}^{-2}$, seguida de uma redução drástica nos valores desse variável com o incremento da população das duas espécies daninhas (Figura 9). 
Este comportamento inicial pode estar relacionado à resposta das plantas feijoeiro à baixas densidades de plantas daninhas, isto é, a planta investe na produção de parte aérea em busca de mais energia luminosa, em contrapartida, com o aumento da densidade de plantas daninhas pertencentes a espécies diferentes o feijoeiro aumenta a produção de sistema radicular em relação a parte aérea. Nesta situação a disputa por nutrientes, água e espaço no ambiente edáfico se torna predominante, destacando-se que neste tratamento o feijoeiro se encontrava em estado de competição com duas espécies de plantas daninhas com características totalmente diferentes.

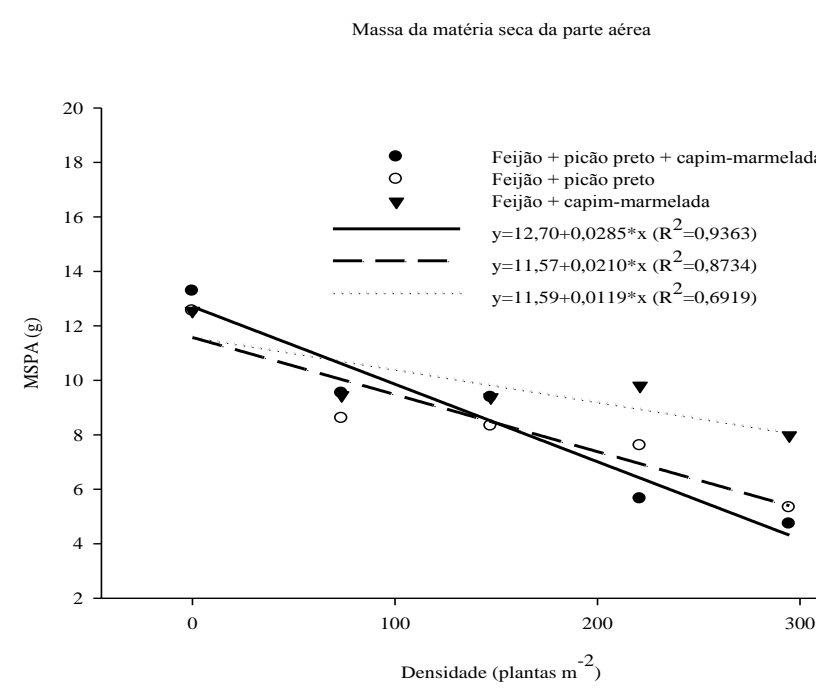

Figura 8. Matéria seca da parte aérea (MSPA) de feijoeiro cultivado em competição com capim-marmelada e picão-preto em diferentes densidades e arranjos

\section{Relação MSPA/MSR}

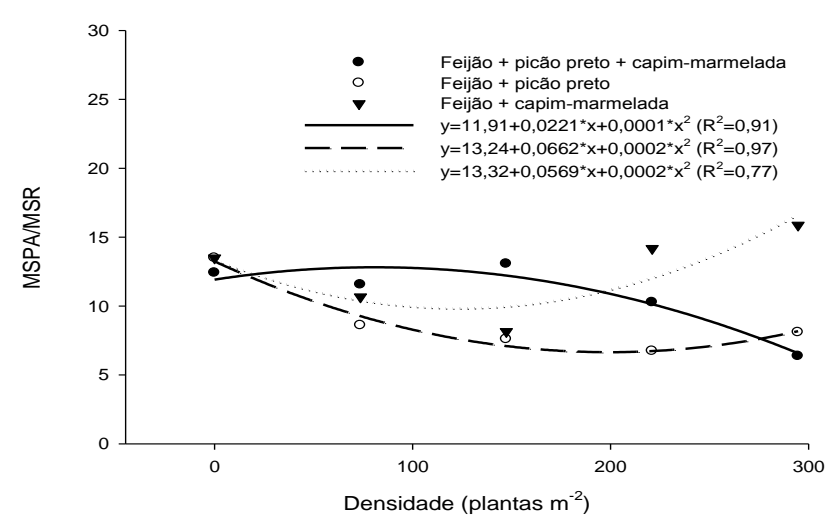

Figura 9. Relação entre parte aérea e radicular (MSPA/MSR) de feijoeiro cultivado em competição com capim-marmelada e picão-preto em diferentes densidades e arranjos.

O incremento da densidade de plantas de picão-preto em competição com o feijoeiro promoveu decréscimo acentuado nos valores da relação MSPA/MSR até a densidade de 147 plantas de picão-preto/m $/ \mathrm{m}^{-2}$, seguida de um pequeno aumento nos valores dessa variável nas duas maiores densidades testadas (Figura 9). Em competição com picão-preto o feijoeiro mostrou maior tendência de incrementar a produção de sistema radicular. Bidens pilosa pode promover elevada extração de nutrientes; quanto maior a extração, maior será o potencial competitivo com a cultura de interesse.

A espécie é capaz de acumular teores e quantidades totais relativamente altos de nitrogênio, fósforo e micronutrientes. Na avaliação realizada no final da formação de propágulos, em substrato com doses crescentes de fósforo, Procópio et al. (2005) observaram que plantas de feijão apresentaram menor conteúdo de matéria seca total de raízes, quando comparada a $B$. pilosa, para todos os níveis estudados de nutrientes.

Ao se avaliar o efeito do aumento da densidade de plantas de capim-marmelada em competição com o feijoeiro na relação MSPA/MSR verificou-se pequeno decréscimo na relação MSPA/MSR seguido no aumento dos valores dessa variável indicando maior produção de parte aérea das plantas de feijoeiro nas maiores densidades (Figura 9). Segundo Santos e Cury (2011), o picão-preto poderia também desempenhar competição mais severa com a cultura já que se trata de uma das mais agressivas espécies no uso da água e de outros recursos do solo nos principais cultivos agrícolas.

Segundo Santos et al. (2006) e Teixeira et al. (2009) a competição entre a planta daninha e a cultivada afeta ambas, porém a espécie daninha quase sempre supera as plantas cultivadas. Levando em consideração esta afirmação, pode-se presumir que plantas daninhas de diferentes espécies, como foi o caso desse experimento, também competem entre si.

Cury et al. (2011) trabalhando com efeito da competição de plantas daninhas na cultura do feijoeiro e nas espécies infestantes concluíram que as diversas relações de competição às quais o feijoeiro é submetido, demonstram que em cada competição há variação do acúmulo e alocação de recursos energéticos (fotoassimilados) nos componentes vegetativos da cultura e das espécies de plantas daninhas, afetando diretamente o crescimento da cultura. Estes autores também constataram que as raízes do feijoeiro foi o principal órgão afetado negativamente pela competição; entre as espécies competidoras as folhas e o caule foram os órgãos mais prejudicados.

\section{Conclusões}

As plantas de picão-preto e capim-marmelada, em convivência de plantas de feijão afetam o crescimento e desenvolvimento da cultura.

O picão-preto exerce maior competição sofre $\mathrm{o}$ feijoeiro do que o capim-marmelada (U. plantaginea). No entanto, a associação das plantas daninhas é mais prejudicial à cultura do que isoladas. 


\section{Agradecimentos}

À Coordenação de Aperfeiçoamento de Pessoal de Nível Superior (CAPES), ao Conselho Nacional de Desenvolvimento Científico e Tecnológico $(\mathrm{CNPq})$ e à Fundação de Amparo à Pesquisa do Estado de Minas Gerais (FAPEMIG), pelo apoio financeiro na execução deste trabalho.

\section{Referências Bibliográficas}

BARCELLOS JUNIOR, L. H.; PEREIRA, G. A. M.; CAPOBIANGO, N. P.; SILVA, D. V.; BRAGA, R. R.; FERREIRA, E. A. Fitossociologia de plantas daninhas em cultivos de feijão sobre diferentes manejos de herbicidas. Revista Brasileira de Herbicidas, Londrina-PR, v. 15, n. 3 , p. 221-231, 2016.

COBUCCI, T. Manejo e controle de plantas daninhas em feijão. In: VARGAS, L.; ROMAN, E. S. Manual de manejo e controle de plantas daninhas. 2. ed. Bento Gonçalves-RS: Embrapa Uva e Vinho, 2008. p. 453-480.

CONAB. Companhia Nacional do Abastecimento. Acompanhamento da safra brasileira: $9^{\circ}$ Levantamento de Safra de 2016/2017. Disponível em: http://www.conab.gov.br/. Acesso em: 21 mar. 2016.

CURY, J. P.; SANTOS, J. B.; VALADÃO SILVA, D.; CARVALHO, F. P.; BRAGA, R. R.; BYRRO, E. C. M.; FERREIRA, E. A. Produção e partição de matéria seca de cultivares de feijão em competição com plantas daninhas. Planta Daninha, Viçosa-MG, v. 29, n. 1, p. 149-158, 2011.

FONTES, J. R. A.; SHIRATSUCHI, L. S.; NEVES, J. L.; JÚLIO, L.; SONDRÉ FILHO, J. Manejo integrado de plantas daninhas. Planaltina-DF: Embrapa-CPAC, 2003. 48 p. (Boletim Técnico, 103).

JAKELAITIS, A.; SILVA, A. F.; PEREIRA, J. L., SILVA, A. A.; FERREIRA, L. R.; VIVIAN, R. Efeitos de densidade e época de emergência de Brachiaria brizantha em competição com plantas de milho. Acta Scientiarum. Agronomy, Maringá-PR, v. 28, n. 3, p. 373-378, 2006.

MANABE, P. M. S. MATOS, C. C.; FERREIRA, E. A.; SILVA, A. F.; SILVA, A. A.; SEDIYAMA, T.; MANABE, A.; ROCHA, P. R. R.; SILVA, C. T. Efeito da competição de plantas daninhas na cultura do feijoeiro. Bioscience Journal, Uberlândia-MG, v. 31, n. 2, p. 333-343, 2015.

PROCÓPIO, S. O.; SANTOS, J. B.; PIRES, F. R.; SILVA, A. A.; MENDONÇA, E. S. Absorção e utilização do fósforo pelas culturas da soja e do feijão e por plantas daninhas. Revista Brasileira de Ciência do Solo, Viçosa-MG, v. 29, n. 6, p. 911-921, 2005.

PROCÓPIO, S. O.; SANTOS, J. B.; SILVA, A. A.; DONAGEMMA, G. K.; MENDONÇA, E. S. Ponto de murcha permanente de soja, feijão e plantas daninhas. Planta Daninha, Viçosa-MG, v. 22, n. 1, p. 35-41, 2004.

RONCHI, C. P.; SILVA, A. A. Efeito na competição de plantas daninhas sobre o crescimento de plantas jovens de café. Planta Daninha, Viçosa-MG, v. 24, n. 3, p. 415-423, 2006.

SALGADO, T. P.; SALLES, M. S.; MARTINS, J. V. F.; ALVES, P. L. C. A. Interferência das plantas daninhas no feijoeiro carioca. Planta Daninha, Viçosa-MG, v. 25, n. 3, p. 443-448, 2007.

SANTOS, J. B.; CURY, J. P. Picão-preto: uma planta daninha especial em solos tropicais. Planta Daninha, Viçosa-MG, v. 29, n. especial, p. 1159-1171, 2011.

SANTOS, J. B.; GAVILANES, M. L. Botânica. In: VIEIRA, C.; PAULA JÚNIOR, T.; BORÉM, A. (Eds). Feijão. 2. ed. Viçosa-MG: Universidade Federal de Viçosa, 2006. p. 41-65.

SANTOS, J. B.; PROCÓPIO, S. O.; SILVA, A. A.; COSTA, L. C. Captação e aproveitamento da radiação solar pelas culturas da soja e do feijão e por plantas daninhas. Bragantia, Campinas-SP, v. 62, n. 1, p. 147-153, 2003.

SILVA, A. A.; SILVA, J. F. Tópicos em manejo de plantas daninhas. 2. ed. Viçosa-MG: UFV, 2013. 62 p.

TAIZ, L.; ZEIGER, E. Fisiologia vegetal. 5. ed. Porto AlegreRS: Artimed, 2014. 719 p.

TEIXEIRA, I. R.; SILVA, R. P.; SILVA, A. G.; FREITAS, R. S. Competição entre feijoeiros e plantas daninhas em função do tipo de crescimento dos cultivares. Planta Daninha, Viçosa-MG, v. 27, n. 2, p. 235-240, 2009. 